\title{
Morphologic and functional outcomes of different optical coherence tomography patterns of myopic foveoschisis after vitrectomy and inner limiting membrane peeling
}

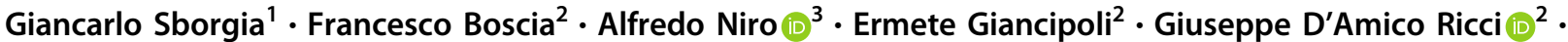 \\ Alessandra Sborgia $^{1,3}$ - Luigi Sborgia ${ }^{1}$. Nicola Recchimurzo ${ }^{1}$ - Mario R. Romano ${ }^{4}$ Giuseppe Addabbo ${ }^{3}$. \\ Giovanni Alessio ${ }^{1}$
}

Received: 29 September 2018 / Revised: 3 May 2019 / Accepted: 24 May 2019 / Published online: 17 June 2019

(c) The Author(s), under exclusive licence to The Royal College of Ophthalmologists 2019

\begin{abstract}
Objective To evaluate the morphologic and functional outcomes of different optical coherence tomography (OCT) patterns of myopic foveoschisis after vitrectomy with Inner Limiting Membrane (ILM) peeling.

Methods In this prospective non-randomised study, 62 consecutive eyes with Myopic Foveoschisis were categorised into three groups according to OCT pattern: retinoschisis type (Rt) Group (23/62), foveal detachment type (FDt) Group (20/62) and macular hole type (MHt) Group (19/62). All patients underwent 25-Gauge vitrectomy and ILM peeling. Air or gas tamponade was used. All patients were observed at month 1, 2, 4 and 6 after surgery. Main outcomes measures: surgical success as resolution of myopic foveoschisis, central retinal thickness (CRT), IS/OS junction recovery and best-corrected visual acuity (BCVA) measurement. Any complication was reported.

Results In all eyes OCT showed a resolution of the retinoschisis, foveal detachment and macular hole pattern, respectively. CRT significantly decreased in all Groups $(p<.001)$, mainly in MHt. IS/OS junction recovery was mainly observed in MHt. BCVA significantly increased in all Groups $(p<.01)$. A functional gain $\geq 2$ Snellen lines occurred in 70,85 and $68 \%$ in the Rt, FDt and MHt Group, respectively. Final BCVA was correlated with preoperative BCVA $(R 0.74, p<0.0001)$, postoperative CRT $(R-0.49, p<0.0001)$, and the recovery of IS/OS junction at 6 months $(R 0.76, p<0.0001)$. Few postoperative complications occurred.

Conclusions Vitrectomy with ILM peeling results in favourable anatomic and functional outcomes for different patterns of myopic foveoschisis.
\end{abstract}

These authors contributed equally: Giancarlo Sborgia, Francesco Boscia, Alfredo Niro

Alfredo Niro

alfynir@gmail.com

1 Department of Medical Science, Neuroscience and Sense Organs, Eye Clinic, University of Bari, Bari, Italy

2 Department of Surgical, Microsurgical and Medical Sciences, Eye Clinic, University of Sassari, Sassari, Italy

3 Eye Clinic, Hospital "S. G. MOSCATI", ASL TA, Taranto, Italy

4 Department of Ophthalmology, Humanitas University, Pieve Emanuele, Milan, Italy

\section{Introduction}

Myopic foveoschisis, described as the splitting of the inner retinal layers in the macular region, affects from 8 to $34 \%$ of high myopic patients and is known to be one of the major causes of significant visual loss in those patients [1-4]. Anterior vitreomacular traction has been suggested as the most probable pathogenic mechanism of myopic foveoschisis [5-12]. Vitreomacular adhesion, epiretinal membrane (ERM), intrinsic noncompliance of the inner limiting membrane are further elements involved in the progression of the disease [5, 6]. Myopic foveoschisis has been associated with a number of possible optical coherence tomography (OCT) features such as foveal detachment or full-thickness macular hole [13-15]. Foveal detachment develops in $34-72 \%$ of patients with myopic foveoschisis [16-18]. Macular hole can occur after a variable period of a 
few months to several years following the development of myopic foveoschisis and foveal detachment [19-21]. Jo et al. reported that surgery is indicated when progression of myopic traction maculopathy and vision impairment occur [15]. Pars plana vitrectomy (PPV), with or without Inner Limiting Membrane (ILM) peeling and gas tamponade has been described by many studies as an effective treatment for myopic foveoschisis complicated or not by foveal detachment or macular hole [15, 18, 22, 23]. Previous studies reported a variable surgery success rate (range, 70-96\%) with or without a significant visual improvement, using different and not standardised surgical procedures. $[3,14,16-18,20,22,24-31]$. The purpose of the study was to evaluate the morphologic and functional outcomes of standardised 25-Gauge vitrectomy and ILM peeling for different tomographic patterns of myopic foveoschisis.

\section{Methods}

We conducted a two-centre, nonrandomised, prospective study on 62 patients affected by myopic foveoschisis who underwent 25-Gauge PPV with ILM peeling. All patients underwent a standard ophthalmologic examination. Macular status was evaluated by using Spectralis (Heidelberg Engineering, Dossenheim, Germany) or Cirrus (Carl Zeiss Meditec, Dublin, USA) spectral-domain OCT devices. Patients with myopic foveoschisis complaining of metamorphopsia and progressive visual decline were included in the study. Data collected included patient gender, age, lens status, axial length, mean refractive error in phakic eyes, OCT pattern of myopic foveoschisis, Central Retinal Thickness (CRT), defects at the inner and outer segment (IS/OS) junction and best-corrected visual acuity (BCVA). Patients who met any of the following criteria were excluded from study entry: macular hole retinal detachment, choroidal neovascularization, macular atrophy, axial length $<26.0 \mathrm{~mm}$ and a follow-up period $<6$ months. The eyes were categorised into three groups according to OCT pattern of myopic foveoschisis: a myopic retinoschisis, characterised by intraretinal cysts separating the retina into a thinner outer layer and a thicker inner layer, and photoreceptors still attached to the retinal pigment epithelium (RPE) at foveal site (Retinoschisis type-Rt); a myopic retinoschisis with foveal detachment characterised by an outer retinal layer detachment from the RPE at foveal site (Foveal Detachment type-FDt); a macular retinoschisis with a full-thickness macular hole (Macular Hole type-MHt). (Fig. 1)

Outcome measurements were: surgical success rate defined as the restoration of the foveal depression with collapse of the schisis cavities in Rt Group, reattachment of detached fovea in FDt Group and the closing of the hole in
MHt Group; IS/OS junction integrity; CRT; BCVA. Safety evaluation has also been performed as regards intraocular pressure (IOP) variations throughout the follow-up period and incidence of ocular adverse events. OCT scans and BCVA test were performed at baseline and after surgery at month 1, 2, 4 and 6. We used the same OCT machine for the same patient pre- and post-operatively.

BCVA was measured by using a standardised ETDRS protocol. Testing was done at a standardised distance $(4 \mathrm{~m})$ under standardised lighting conditions. ETDRS values were converted into $\log$ MAR values for the purpose of statistical analysis. A written informed consent was obtained from all patients after the full explanation of the purpose and possible complications of surgery.

\section{Surgical technique}

Cataract surgery was performed in all phakic eyes. A 25Gauge transconjunctival sutureless vitrectomy system was used for 3-port PPV. Core vitrectomy was performed with the creation of a posterior vitreous detachment if it was not present. Triamcinolone acetonide (TA) $(0.2 \mathrm{ml}$ of $20 \mathrm{mg} / \mathrm{ml})$ was injected into the vitreous cavity to visualise the vitreous. The vitreous cortex adhering to the inner retinal surface was removed. Brilliant Blue dye was sprayed onto the posterior retina to stain the ILM. The ILM peeling was performed and peeled over two to three disc diameters using intraocular forceps. In Rt Group air tamponade was performed. Instead in FDt and MHt Group 24\% sulfur hexafluoride (SF6) was used as tamponade and the patients were instructed to remain prone for at least 1 week. Surgical procedures were performed by one surgeon (F.B.).

\section{Statistical analysis}

The qualitative variables are presented as frequencies and percentages, while quantitative data as means \pm standard deviations. Differences between different sample sizes were assessed using Pearson's chi-squared test for categorical variables, and paired $T$ test, unpaired $T$ test, Kruskal-Wallis test or one-way analysis of variance (ANOVA) followed by post hoc Tukey's HSD test for quantitative ones. A categorization of the eyes according the lens status (phakic and pseudophakic) at baseline and a comparison of the functional data as preoperative BCVA, last follow-up BCVA and mean BCVA improvement in each group were performed.

Analysis of covariance (ANCOVA) was used to compare 6 months CRT and BCVA changes of different sample sizes (Rt, FDt and MHt Group), adjusting values for the baseline measurements. The analysis of the correlation between BCVA and morphologic outcomes (CRT and IS/OS junction integrity) was based on the observed data collected 

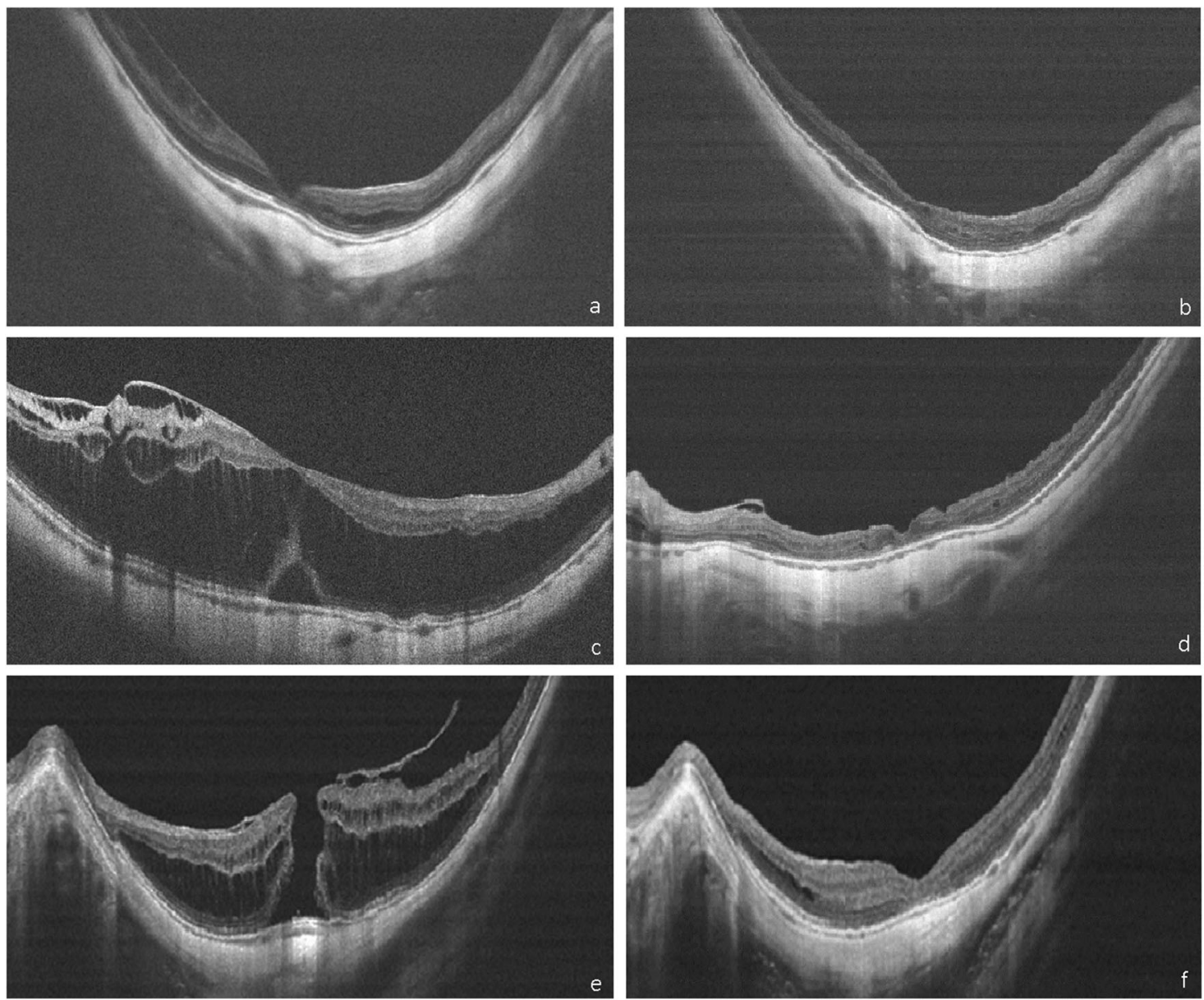

Fig. 1 Representative optical coherence tomography scans of the three different patterns of Myopic foveoschisis before and after surgery. Representative spectral-domain optical coherence tomography scans of the three different patterns at baseline (left side) and at 6 months after vitrectomy and ILM peeling (right side). (First row, a, b) In this pseudophakic eye with retinoschisis (Rt) visual acuity improved from

during the 6-month follow-up and examined by Pearson correlation coefficient.

$P$ value $<0.05$ was considered statistically significant. Preoperative and postoperative data were analysed using $\mathrm{R}$ (v 3.3.1) and Rstudio (v 1.0.153).

\section{Results}

\section{Baseline characteristics}

We selected 62 eyes of 62 consecutive patients out of 79 patients affected by myopic foveoschisis. Forty-one eyes were phakic and 21 pseudophakic. Five patients affected by Rt rejected surgery approach; two patients affected by Rt and three patients affected by FDt missed surgery after that a major systemic pathology was diagnosed; six patients
0.22 to 0.09 Logmar. (Second row, $\mathbf{c}, \mathbf{d}$ ) In this phakic eye affected by retinoschisis with foveal detachment (FDt) visual acuity improved from 0.9 to 0.4 Logmar. (Bottom row, e, f) In this phakic eye affected by retinoschisis with full-thickness macular hole (MHt) visual acuity improved from 1.2 to 0.8 Logmar

decided to undergo surgery in another centre; one patient missed the appointment for surgery.

All selected patients complained progressive visual impairment and metamorphopsia in the previous months. The mean overall age was $59 \pm 10$ years (range, 31-84 years). Mean overall axial length was $30.39 \pm 2.02 \mathrm{~mm}$ (range, 26.02-34.81 $\mathrm{mm}$ ) and mean refractive error in 46 phakic eyes was $-13.6 \pm 4.7$ diopters (D) (range, -21 to -3D) (Table 1).

OCT classified 23 eyes in Rt Group, 20 eyes in FDt Group and 19 eyes in MHt Group. Among the Groups there was a significant difference in the preoperative CRT $(p<.001)$. OCT scans revealed a defect in the IS/OS junction at foveal site in all Groups. Among the Groups there was a significant difference in the preoperative BCVA $(p=.01)$, mainly observed among phakic eyes $(p<.01)$. (Table 2) 
Table 1 Baseline characteristics of the patients

\begin{tabular}{lllll}
\hline Category & Rt group $(n=23)$ & FDt group $(n=20)$ & MHt group $(n=19)$ & $p$-value \\
\hline Age (mean $\pm S D)$, years & $61 \pm 12$ & $55 \pm 9$ & $60 \pm 7$ & $0.104^{\mathrm{a}}$ \\
Sex (male/female) & $5 / 18$ & $9 / 11$ & $10 / 9$ & $0.094^{\mathrm{b}}$ \\
Phakic/Pseudophakic & $17 / 6$ & $13 / 7$ & $11 / 8$ & $0.546^{\mathrm{b}}$ \\
Axial length (mean $\pm \mathrm{SD}), \mathrm{mm}$ & $30.5 \pm 1.5$ & $30.7 \pm 2.4$ & $28.7 \pm 3.6$ & $0.223^{\mathrm{a}}$ \\
\hline
\end{tabular}

$R t$, Retinoschisis type; $F D t$, foveal detachment type; $M H t$, Macular Hole type; $S D$, standard deviation $p$-value between Rt group, FDt group and MHt group

${ }^{a}$ Kruskal-Wallis Test

${ }^{\mathrm{b}}$ Chi-Square Test

\section{Anatomic results}

All eyes (100\%) had a complete resolution of the macular foveoschisis pattern at least 4 months after surgery. In particular, all macular holes achieved closure defined as a flattened and reattached hole rim along the whole circumference (Fig. 1).

In Rt Group mean CRT decreased to $308 \pm 62 \mu \mathrm{m}, 285 \pm$ $68 \mu \mathrm{m}, 277 \pm 61 \mu \mathrm{m}$ and $271 \pm 59 \mu \mathrm{m}$ at month $1,2,4$ and 6 , respectively $(p<.001)$; in FDt Group mean CRT decreased to $350 \pm 68 \mu \mathrm{m}, 321 \pm 49 \mu \mathrm{m}, 303 \pm 47 \mu \mathrm{m}$ and $292 \pm 45 \mu \mathrm{m}$ at month $1,2,4$ and 6 , respectively $(p<.001)$; in MHt Group mean CRT decreased to $268 \pm 67 \mu \mathrm{m}, 241 \pm 58 \mu \mathrm{m}, 220 \pm$ 59 and $216 \pm 50 \mu \mathrm{m}$ at month $1,2,4$ and 6 , respectively ( $p$ $<.001)$. Mean reduction of CRT was significantly different between the Groups $(p<.001)$ (Table 2$)$.

ANCOVA analysis revealed that last mean CRT was lower of $7.2 \mu \mathrm{m}$ (IC 95\%, 33-47; $p=.72$ ) in FDt and 76.9 $\mu \mathrm{m}$ (IC 95\%: $39.75-114.10 ; p<.001$ ) in MHt Group compared to Rt Group.

At 6 months OCT revealed the recovery of IS/OS junction in $38.5 \%(10 / 26)$ of patients with photoreceptor defect at baseline (Table 2).

Only in MHt Group a significant correlation between last CRT and final BCVA was observed. A significant correlation between IS/OS recovery and last BCVA was observed (Table 3).

\section{Visual results}

In Rt and FDt Groups mean BCVA significantly improved at all time points $(p<.01)$. In MHt Group BCVA significantly improved at 6 months after surgery $(p=.01)$ (Fig. 2, Table 2).

Mean visual improvement was significantly different between the groups $(p=0.03)$. At last follow-up, the visual improvement was $\geq 2$ Snellen lines in 70,85 and $68 \%$ of eyes in Rt, FDt and MHt Group, respectively. BCVA decreased of $\geq 2$ Snellen lines only in 13,5 and $16 \%$ of eyes in Rt, FDt and MHt Group, respectively, (Table 2).
Among the Groups there was a significant difference in final BCVA, mainly in phakic eyes.

ANCOVA analysis revealed that last mean BCVA was lower of $0.05 \operatorname{LogMAR}$ (IC 95\%, 0.22-0.11; $=.5$ ) in FDt and higher of 0.32 LogMAR (IC 95\%, 0.15-0.50; $p<.001$ ) in MHt Group compared to Rt Group.

In all groups a significant correlation between baseline and last BCVA was observed (Table 3).

\section{Complications}

We did not report macular hole as complication after vitrectomy. During follow-up choroidal neovascularization (CNV) developed in two eyes (3\%), macular atrophy in five eyes $(8 \%)$ and macular oedema in two eyes (3\%). The only case of choroidal detachment reported occurred intraoperative and was caused by a valsalva maneuver due to emesis. No other serious complications, including endophthalmitis, postoperative increase of IOP, postoperative hypotony or intraocular inflammation, were seen in this study.

\section{Discussion}

Myopic foveoschisis can occur as retinoschisis feature, proceeds to foveal detachment and finally causes a full-thickness macular hole. In highly myopic eyes disease progression is largely debatable, and indication for and timing of surgery deserve a standardisation. The accumulated data are insufficient to prove whether vitrectomy benefits all types of myopic foveoschisis [19, 20, 24, 32-34]. The rationale for PPV and ILM peeling is based on the presence of tractional forces that can be effectively relieved by means of this approach.

To our knowledge, only three prospective studies are reported in literature. Figueroa et al. demonstrated the efficacy of ILM peeling and gas tamponade with low postoperative complications. In this study surgery was performed by three different surgeons [35]. Shin et al. 
Table 2 Anatomic and functional outcomes after 25-Gauge vitrectomy with ILM peeling

\begin{tabular}{|c|c|c|c|c|}
\hline & Rt group & FDt group & MHt group & $p$-value \\
\hline \multicolumn{5}{|l|}{$\begin{array}{l}\text { Central retinal } \\
\text { thickness, } \mu \mathrm{m}\end{array}$} \\
\hline Preoperative & $409 \pm 99$ & $618 \pm 84$ & $571 \pm 131$ & $<0.001^{\mathrm{a}}$ \\
\hline $\begin{array}{l}\text { Postoperative } \\
\text { (final) }\end{array}$ & $271 \pm 59$ & $292 \pm 45$ & $216 \pm 50$ & $<0.001^{\mathrm{a}}$ \\
\hline p-value & $<0.001^{\mathrm{b}}$ & $<0.001^{\mathrm{b}}$ & $<0.001^{\mathrm{b}}$ & \\
\hline $\begin{array}{l}\text { Mean reduction in } \\
\text { CRT, } \mu \mathrm{m}\end{array}$ & $138 \pm 93$ & $325 \pm 91$ & $354 \pm 127$ & $<0.001^{\mathrm{a}}$ \\
\hline $\begin{array}{l}\text { Preop IS/OS defect, } \\
n(\%)\end{array}$ & $3(13)$ & $4(25)$ & $19(100)$ & $<0.001^{\mathrm{c}}$ \\
\hline $\begin{array}{l}\text { Postop IS/OS } \\
\text { recovery, } n(\%)\end{array}$ & $1(33)$ & $1(25)$ & $8(42)$ & $0.80^{\mathrm{c}}$ \\
\hline$p$-value & $0.32^{\mathrm{b}}$ & $0.16^{\mathrm{b}}$ & $<0.01^{\mathrm{b}}$ & \\
\hline \multicolumn{5}{|l|}{ BCVA, logMar } \\
\hline Preoperative & $0.61 \pm 0.41$ & $0.93 \pm 0.58$ & $1.11 \pm 0.57$ & $0.01^{\mathrm{a}}$ \\
\hline $\begin{array}{l}\text { Postoperative } \\
\text { (final) }\end{array}$ & $0.29 \pm 0.31$ & $0.41 \pm 0.39$ & $0.88 \pm 0.45$ & $<0.001^{\mathrm{a}}$ \\
\hline$p$-value & $<0.01^{\mathrm{b}}$ & $<0.01^{\mathrm{b}}$ & $0.01^{\mathrm{b}}$ & \\
\hline $\begin{array}{l}\text { Mean improvement } \\
\text { in BCVA, logMar }\end{array}$ & $0.32 \pm 0.30$ & $0.52 \pm 0.41$ & $0.22 \pm 0.36$ & $0.03^{\mathrm{a}}$ \\
\hline \multicolumn{5}{|l|}{$\begin{array}{l}\text { Final change in } \\
\text { BCVA, } n(\%)\end{array}$} \\
\hline $\begin{array}{l}\text { Improve }(\geq 2 \\
\text { Snellen lines) }\end{array}$ & $16(70)$ & 17 (85) & $13(68)$ & $0.53^{c}$ \\
\hline $\begin{array}{l}\text { Worsened ( } \geq 2 \\
\text { Snellen lines) }\end{array}$ & $3(13)$ & $1(5)$ & $3(16)$ & \\
\hline \multicolumn{5}{|l|}{$\begin{array}{l}\text { Baseline } \\
\text { BCVA, logMar }\end{array}$} \\
\hline Phakic & $0.51 \pm 0.37$ & $1.08 \pm 0.65$ & $1.17 \pm 0.72$ & $<0.01^{\mathrm{a}}$ \\
\hline Pseudophakic & $0.89 \pm 0.42$ & $0.67 \pm 0.27$ & $1.01 \pm 0.25$ & $0.13^{\mathrm{a}}$ \\
\hline$p$-value & $0.09^{d}$ & $0.07^{\mathrm{d}}$ & $0.51^{\mathrm{d}}$ & \\
\hline \multicolumn{5}{|l|}{$\begin{array}{l}\text { Final } \\
\text { BCVA, logMar }\end{array}$} \\
\hline Phakic & $0.24 \pm 0.26$ & $0.41 \pm 0.42$ & $0.90 \pm 0.55$ & $<0.001^{\mathrm{a}}$ \\
\hline Pseudophakic & $0.45 \pm 0.40$ & $0.40 \pm 0.37$ & $0.86 \pm 0.30$ & $0.04^{\mathrm{a}}$ \\
\hline$p$-value & $0.26^{\mathrm{d}}$ & $0.94^{\mathrm{d}}$ & $0.85^{\mathrm{d}}$ & \\
\hline \multicolumn{5}{|l|}{$\begin{array}{l}\text { Mean improvement } \\
\text { in BCVA, logMar }\end{array}$} \\
\hline Phakic & $0.26 \pm 0.29$ & $0.60 \pm 0.41$ & $0.31 \pm 0.31$ & $0.02^{\mathrm{a}}$ \\
\hline Pseudophakic & $0.44 \pm 0.22$ & $0.24 \pm 0.14$ & $0.14 \pm 0.39$ & $0.18^{\mathrm{a}}$ \\
\hline$p$-value & $0.15^{\mathrm{d}}$ & $0.01^{\mathrm{d}}$ & $0.35^{\mathrm{d}}$ & \\
\hline
\end{tabular}

$R t$, retinoschisis type; $F D t$, foveal detachment type; $M H t$, macular hole type; $B C V A$, best-corrected visual acuity; IS/OS, inner segment/outer segment

${ }^{\mathrm{a}} p$-value among Rt, FDt and MHt groups (ANOVA test)

${ }^{\mathrm{b}} p$-value between preoperative and postoperative final visit at 6 months (final) values (Paired $T$-test)

${ }^{c} p$-value among Rt, FDt and MHt groups (Chi-Square Test)

${ }^{\mathrm{d}} p$-value between phakic and pseudophakic eyes in each group (Unpaired $T$-test)
Table 3 Correlation between 6-months best-corrected visual acuity and morpho-functional outcomes

\begin{tabular}{|c|c|c|c|c|}
\hline & All & $\begin{array}{l}\text { Rt } \\
\text { group }\end{array}$ & $\begin{array}{l}\text { FDt } \\
\text { group }\end{array}$ & $\begin{array}{l}\text { MHt } \\
\text { group }\end{array}$ \\
\hline \multicolumn{5}{|c|}{ Preoperative CRT, $\mu \mathrm{m}$} \\
\hline$R^{\mathrm{a}}$ & 0.16 & -0.32 & 0.14 & 0.05 \\
\hline$p$-value & 0.19 & 0.14 & 0.53 & 0.82 \\
\hline \multicolumn{5}{|c|}{ Postoperative CRT, $\mu \mathrm{m}$} \\
\hline$R^{\mathrm{a}}$ & -0.49 & -0.35 & -0.03 & -0.59 \\
\hline$p$-value & $<0.0001$ & $1 \quad 0.09$ & 0.88 & $<0.01$ \\
\hline \multicolumn{5}{|c|}{$\begin{array}{l}\text { Postoperative IS/OS } \\
\text { recovery }\end{array}$} \\
\hline$R^{\mathrm{a}}$ & 0.76 & 0.56 & 0.72 & 0.70 \\
\hline$p$-value & $<0.0001$ & $1<0.01$ & $<0.001$ & $<0.001$ \\
\hline \multicolumn{5}{|c|}{ Preoperative BCVA, logMar } \\
\hline$R^{\mathrm{a}}$ & 0.74 & 0.61 & 0.70 & 0.77 \\
\hline$p$-value & $<0.0001$ & 0.001 & $<0.001$ & 0.0001 \\
\hline \multicolumn{5}{|c|}{$R^{\mathrm{a}}$ Pearson correlation coefficient } \\
\hline \multicolumn{5}{|c|}{$\begin{array}{l}R t \text {, retinoschisis type; } F D t \text {, foveal detachment type; } M H t \text {, macular hole } \\
\text { type; } B C V A \text {, best-corrected visual acuity; IS/OS, inner segment/outer } \\
\text { segment }\end{array}$} \\
\hline
\end{tabular}

reported a significant improvement in BCVA and reduction of CRT after ILM peeling [15]. Moreover, in both studies patients were not categorised according to OCT pattern of foveoschisis. Al-Badawi et al., in a recent paper, described good morphologic and functional results using a non-foveasparing ILM peeling in 21 eyes with different myopic foveoschisis patterns [36]. However, the eyes were categorised only into two groups (with or without $\mathrm{MH}$ ), not recognizing retinoschisis or foveal detachment patterns. In our series the high surgical success rate $(100 \%)$ in all three groups, meaning a complete resolution of the foveal retinoschisis, reattachment of foveal detachment or closing of macular hole, is in line with previous papers [11, 13, 15-18, 22-25, 32, 37]. Furthermore, as points of strength of our study, we highlight that the patients enrolled represents the biggest high myopic Caucasian population with macular foveoschisis reported in literature, the patients were enrolled according to specific inclusion tomographic criteria, and all surgical procedures were performed by a single experienced surgeon by using a well standardised technique.

Single group mean CRT significantly decreased at all follow-up, mainly in MHt Group with a mean reduction of $354.74 \mu \mathrm{m}$. Only in MHt Group mean CRT was significantly lower at 6 months compared to Rt Group as control group. If OCT revealed that macular atrophy occurred in $26 \%$ of eyes in MHt Group, in the same group IS/OS defect recovery occurred in about $42 \%$ of eyes whose final CRT was $\geq 240 \mu \mathrm{m}$. As previously reported, IS/OS recovery occurred in eyes with thicker central retina after 
Fig. 2 BCVA changes after surgery for all three groups. In Rt Group, BCVA is significantly better at all follow-up visits than that at baseline. In the FDt Group, BCVA significantly improves at month 2, 4 and 6 . In MHt Group, 6-month BCVA is significantly better than BCVA at baseline. *level of significance, $p=0.01$. **level of significance, $p<0.01$. $* * *$ level of significance, $p=$ 0.001

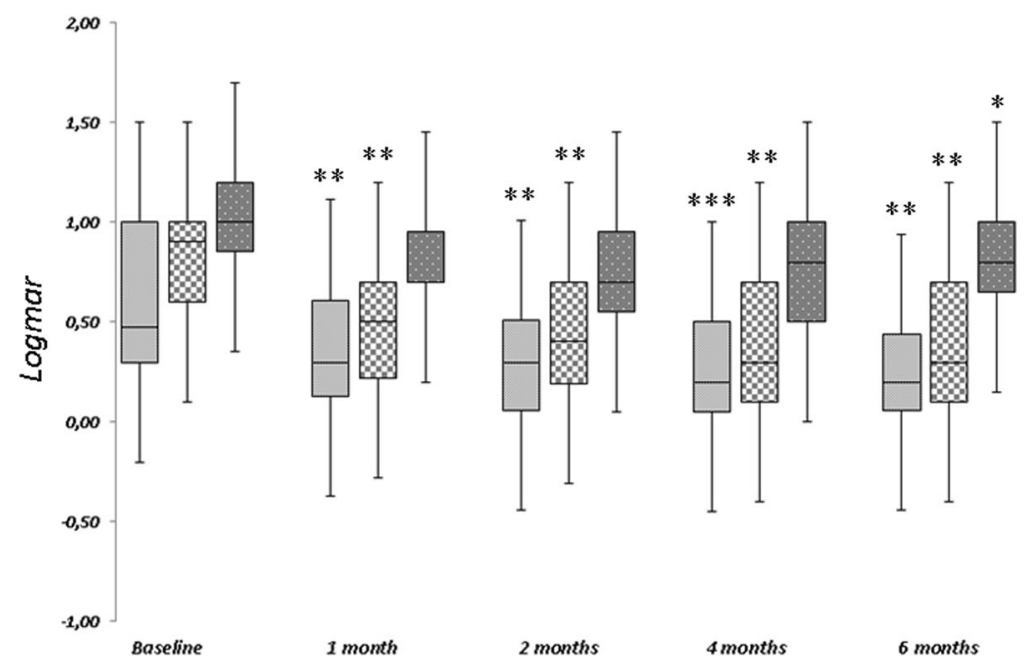

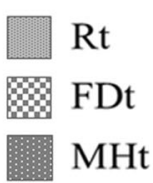

foveoschisis to choose tamponade. Using gas tamponade with or without ILM peeling for foveal detachment feature, foveal reattachment and resolution of myopic foveoschisis is usually achieved, but full resolution has been reported to take as long as 6 months $[22,37]$ as occurred in our study. These results can be explained by the push of the gas on detached neuroretina to RPE, furthering the pumping out of subretinal fluid by RPE cells, and the weakening of residual vitreomacular tractions. Hirakata and Hida [32] hypothesised that both gas tamponade and ILM peeling for foveal detachment pattern might lead to an iatrogenic macular hole, but in our series, as in other papers [17, 36], none iatrogenic macular hole occurred. In macular hole pattern the tangential tension on the inner retina cannot be eliminated completely by vitreous surgery and ILM peeling. So, gas tamponade can further a complete relaxation of the retina, smoothing the borders of the hole on underlying bare pigment epithelium. Furthermore, the high surgical success rate in Rt could suggest the air, as a shorter-acting gas, might provide a sufficiently long tamponade effect when foveoschisis is not complicated by foveal neuroretinal detachment or macular hole.

In all groups last BCVA was significantly correlated with baseline BCVA and the majority of patients reported a visual improvement $\geq 2$ Snellen line at 6 months (Rt, 70\%; FDt, $85 \%$; MHt, 68\%). The significant visual improvement in the Rt after surgery might suggest that even eyes without foveal detachment or macular hole can be associated with functional impairment, justifying surgery approach. However, the visual improvement in the Rt was lower than that in the FDt. Indeed, if the 6-months visual acuity was the highest in Rt, in FDt the mean visual improvement was higher compared to the other groups. Different investigators reported good functional outcomes in foveal detachment pattern [18, 24, 28, 32, 35, 45]. Other studies suggested that ILM peeling is effective only for foveal detachment pattern lved faster when gas tamponade was perform $[25,37]$. Moreover they did not consider the OCT pattern of 
$[40,44]$. Ikuno et al. suggested that patients with foveal detachment can obtain the most functional benefit from surgery compared to other patterns [18].

In foveal detachment pattern failure to achieve a complete reattachment could be due to ILM and/or vitreous cortex remnants that can still cause retinal contraction, so their complete removal would allow the retinal distension and the reattachment of photoreceptor to the underlay RPE that should lead to visual recovery. Among all groups only few eyes $(7 / 62,11 \%)$ had a visual worsening $\geq 2$ Snellen lines due to complications occurred such as macular oedema or $\mathrm{CNV}$ in Rt and FDt groups and macular atrophy in MHt group.

Limitations of our study are the short follow-up period and cataract removal at the same time of vitrectomy performed in $57 \%$ of eyes, therefore, no strong conclusions can be made with respect to the visual improvement. In conclusion, our results show that a standardised 25-Gauge vitrectomy with ILM peeling results in high surgical success rate for eyes with different OCT pattern of myopic foveoschisis. The photoreceptor layer recovery could be obtained although macular atrophy could occur.

\section{Summary}

\section{What was known before}

- Vitrectomy efficacy on different OCT patterns of myopic foveoschisis is debatable. Outcomes analysis according to strict OCT categorization is missed.

\section{What this study adds}

- Standardised PPV with ILM peeling results in favorable outcomes in all patterns of myopic foveoschisis Better visual recovery is achived in Foveal Detachment pattern Variable OCT changes occurr in Macula Hole pattern.

\section{Compliance with ethical standards}

Conflict of interest The authors declare that they have no conflict of interest.

Publisher's note: Springer Nature remains neutral with regard to jurisdictional claims in published maps and institutional affiliations.

\section{References}

1. Takano M, Kishi S. Foveal retinoschisis and retinal detachment in severely myopic eyes with posterior staphyloma. Am J Ophthalmol. 1999;128:472-6.
2. Shin HJ, Chung H, Kim HC. Correlation of foveal microstructural changes with vision after anti-vascular endothelial growth factor therapy in age-related macular degeneration. Retina. 2013; 33:964-70.

3. Panozzo G, Mercanti A. Optical coherence tomography findings in myopic traction maculopathy. Arch Ophthalmol. 2004;122:1455-60.

4. Lim LS, Cheung G, Lee SY. Comparison of spectral domain and swept-source optical coherence tomography in pathological myopia. Eye(Lond). 2014;28:488-91.

5. VanderBeek BL, Johnson MW. The diversity of traction mechanisms in myopic traction maculopathy. Am J Ophthalmol. 2012;153:93-102.

6. Johnson MW. Myopic traction maculopathy: pathogenic mechanisms and surgical treatment. Retina. 2012;32:S205-10.

7. Ikuno Y, Gomi F, Tano Y. Potent retinal arteriolar traction as a possible cause of myopic foveoschisis. Am J Ophthalmol. 2005;139:462-7.

8. Baba T, Ohno-Matsui K, Futagami S, Yoshida T, Yasuzumi K, Kojima A, et al. Prevalence and characteristics of foveal retinal detachment without macular hole in high myopia. Am J Ophthalmol. 2003;135:338-42.

9. Sayanagi K, Morimoto Y, Ikuno Y, Tano Y. Spectral-domain optical coherence tomographic findings in myopic foveoschisis. Retina. 2010;30:623-8.

10. Bando H, Ikuno Y, Choi JS, Tano Y, Yamanaka I, Ishibashi T. Ultrastructure of internal limiting membrane in myopic foveoschisis. Am J Ophthalmol. 2005;139:197-9.

11. Spaide RF, Fisher Y. Removal of adherent cortical vitreous plaques without removing the internal limiting membrane in the repair of macular detachments in highly myopic eyes. Retina. 2005;25:290-5.

12. Sayanagi K, Ikuno Y, Gomi F, Tano Y. Retinal vascular microfolds in highly myopic eyes. Am J Ophthalmol. 2005;139:658-63.

13. Mateo C, Dutra Medeiros M, Alkabes M, Burés-Jelstrup A, Postorino M, Corcóstegui B. Illuminated Ando plombe for optimal positioning in highly myopic eyes with vitreoretinal diseases secondary to posterior staphyloma. JAMA Ophthalmol. 2013;131:1359-62.

14. Shin JY, Yu HG. Visual prognosis and spectral-domain optical coherence tomography findings of myopic foveoschisis surgery using 25-gauge transconjunctival sutureless vitrectomy. Retina. 2012;32:486-92.

15. Jo Y, Ikuno Y, Nishida K. Retinoschisis: a predictive factor in vitrectomy for macular holes without retinal detachment in highly myopic eyes. Br J Ophthalmol. 2012;96:197-200.

16. Fang X, Weng Y, Xu S, Chen Z, Liu J, Chen B, et al. Optical coherence tomographic characteristics and surgical outcome of eyes with myopic foveoschisis. Eye (Lond). 2009;23:1336-42.

17. Ikuno Y, Sayanagi K, Ohji M, Kamei M, Gomi F, Harino S, et al. Vitrectomy and internal limiting membrane peeling for myopic foveoschisis. Am J Ophthalmol. 2004;137:719-24.

18. Ikuno Y, Sayanagi K, Soga K, Oshima Y, Ohji M, Tano Y. Foveal anatomical status and surgical results in vitrectomy for myopic foveoschisis. Jpn J Ophthalmol. 2008;52:269-76.

19. Benhamou N, Massin P, Haouchine B, Erginay A, Gaudric A. Macular retinoschisis in highly myopic eyes. Am J Ophthalmol. 2002;133:794-800.

20. Gaucher D, Haouchine B, Tadayoni R, Massin P, Erginay A, Benhamou N, et al. Long-term follow-up of high myopic foveoschisis: natural course and surgical outcome. Am J Ophthalmol. 2007; 143:455-62.

21. Sun CB, Liu Z, Xue AQ, Yao K. Natural evolution from macular retinoschisis to full-thickness macular hole in highly myopic eyes. Eye (Lond). 2010;24:1787-91. 
22. Kwok AK, Lai TK, Yip WW. Vitrectomy and gas tamponade without internal limiting membrane peeling for myopic foveoschisis. Br J Ophthalmol. 2005;89:1180-3.

23. Babba T, Kanaka S, Maesawa A, Teramatsu T, Noda Y, Yamamoto S. Scleral buckling with macular plombe for eyes with myopic macular retinoschisis and retinal detachment without macular hole. Am J Ophthalmol. 2006;142:483-7.

24. Kim KS, Lee SB, Lee WK. Vitrectomy and internal limiting membrane peeling with and without gas tamponade for myopic foveoschisis. Am J Ophthalmol. 2012;153:320-6.

25. Hirakata A, Hida T. Vitrectomy for myopic posterior retinoschisis or foveal detachment. Jpn J Ophthalmol. 2006;50:53-61.

26. Panozzo G, Mercanti A. Vitrectomy for myopic traction maculopathy. Arch Ophthalmol. 2007;125:767-72.

27. Taniuchi S, Hirakata A, Itoh Y, Hirota K, Inoue M. Vitrectomy with or without internal limiting membrane peeling for each stage of myopic traction maculopathy. Retina. 2013;33:2018-25.

28. Kumagai K, Furukawa M, Ogino N, Larson E. Factors correlated with postoperative visual acuity after vitrectomy and internal limiting membrane peeling for myopic foveoschisis. Retina. 2010;30:874-80.

29. Fujimoto S, Ikuno Y, Nishida K. Postoperative optical coherence tomographic appearance and relation to visual acuity after vitrectomy for myopic foveoschisis. AmJ Ophthalmol. 2013; 156:968-73.

30. Lim SJ, Kwon YH, Kim SH, You YS, Kwon OW. Vitrectomy and internal limiting membrane peeling without gas tamponade for myopic foveoschisis. Graefes Arch Clin Exp Ophthalmol. 2012;250:1573-7.

31. Uchida A, Shinoda H, Koto T, Mochimaru H, Nagai N, Tsubota K, et al. Vitrectomy for myopic foveoschisis with internal limiting membrane peeling and no gas tamponade. Retina. 2014;34:455-60.

32. Hotta K, Hotta J. Retinoschisis with macular retinal detachment associated with vitreomacular traction syndrome. Retina. 2004;24:307-9.

33. Yeh SI, Chang WC, Chen LJ. Vitrectomy without internal limiting membrane peeling for macular retinoschisis and foveal detachment in highly myopic eyes. Acta Ophthalmol. 2008; 86:219-24.
34. Sayanagi K, Ikuno Y, Tano Y. Reoperation for persistent myopic foveoschisis after primary vitrectomy. Am J Ophthalmol. 2006;141:414-7.

35. Figueroa MS, Ruiz-Moreno JM, Gonzalez del Valle F, Govetto A, de la Vega C, Plascencia RN, et al. Long-term outcomes of 23gauge pars plana vitrectomy with internal limiting membrane peeling and gas tamponade for myopic traction maculopathy: a prospective study. Retina. 2015;35:1836-43.

36. Al-Badawi AH, Abdelhakim MASE, Macky TA, Mortada HA. Efficacy of non-fovea-sparing ilm peeling for symptomatic myopic foveoschisis with and without macular hole. $\mathrm{Br} \mathrm{J}$ Ophthalmol. 2018. pii: bjophthalmol-2017-311775.

37. Ikuno Y, Tano Y. Early macular holes with retinoschisis in highly myopic eyes. Am J Ophthalmol. 2003;136:741-4.

38. Shao Q, Xia H, Heussen FMA, Ouyang Y, Sun X, Fan Y. Postoperative anatomical and functional outcomes of different stages of high myopia macular hole. BMC Ophthalmol. 2015;7:93-100.

39. Hwang JU, Joe SG, Lee JY, Kim JG, Yoon YH. Microincision vitrectomy surgery for myopic foveoschisis. Br J Ophthalmol. 2013;97:879-84.

40. Germano RAS, Zacharias LC, Takahashi WY. Recurrent myopic foveoschisis: resolution after internal limiting membrane removal. Arq Bras Oftalmol. 2015;78:44-6.

41. Shimada N, Sugamoto Y, Ogawa M, Takase H, Ohno-Matsui K. et al. Fovea-sparing internal limiting membrane peeling for myopic traction maculopathy. Am J Ophthalmol. 2012;154:693-701.

42. Ho TC, Chen MS, Huang JS, Shih YF, Ho H, Huang YH. Foveola nonpeeling technique in internal limiting membrane peeling of myopic foveoschisis surgery. Retina. 2012;32:631-4.

43. Steel DHW, Lotery AJ. Idiopathic vitreomacular traction and macular hole: a comprehensive review of pathophysiology, diagnosis, and treatment. Eye (Lond). 2013;27:S1-S21.

44. Lee CL, Wu WC, Chen KJ, Chiu LY, Wu KY, Chang YC. Modified internal limiting membrane peeling technique (maculorrhexis) for myopic foveoschisis surgery. Acta Ophthalmol. 2017;95:128-31.

45. Mii M, Matsuoka M, Matsuyama K, Otsu $Y$, Nishimura $T$. Favorable anatomic and visual outcomes with 25-gauge vitrectomy for myopic foveoschisis. Clin Ophthalmol. 2014;12:1837-44. 